\title{
Quercetin modulates age-induced changes in the transcript levels of some apoptosis related genes in the skeletal muscles of male rats
}

\author{
Abeer Alm-Eldeen ${ }^{(* 1}$, Abeer Khamis ${ }^{2}$, Nabil Elfiky ${ }^{1}$, Randa Ahmad ${ }^{1}$ \\ ${ }^{1}$ Zoology Department, Faculty of Science, Tanta University, Tanta, Egypt, ${ }^{2}$ Biochemistry \\ Division, Chemistry Department, Faculty of Science, Tanta University, Tanta, Egypt
}

\begin{abstract}
Adverse changes occur gradually in the skeletal muscles with age via continuous exposure to oxidative stress. Quercetin, a member of the flavonoids family, possesses anti-oxidative and radical-scavenging activities. Therefore, this study investigated the role of quercetin to modulate age-induced changes in the transcript levels of some apoptosis-related genes in rat's gastrocnemius muscles, up to 15 months-old. Half of the rats at each age $(1,5,10$ and 15 months old) were given a vehicle and the other half was given $200 \mathrm{mg} / \mathrm{kg}$ quercetin for 2 weeks, respectively. With the increase of age, vehicle groups showed hyalinization of the muscle fibers and a decrease of the catalase and an increase of the malondialdehyde levels. Down-regulation of Bcl2 gene and upregulation of both NF- $\mathrm{KB}$ and Bax genes were recorded. Interestingly, quercetin groups showed focal hyalinization of the muscle fibers at both $10^{\text {th }}$ and $15^{\text {th }}$ months old. An increase in the catalase and a decrease in malondialdehyde levels, up-regulation of Bcl2 gene and down-regulation of both $\mathrm{NF}-\mathrm{KB}$ and Bax genes were recorded. In conclusion, quercetin minimized age-induced alteration in the morphological structure and the expression of the apoptosis-related genes via increasing the antioxidant defense in the gastrocnemius muscle.
\end{abstract}

Keywords: Quercetin. Age, Bcl2. Bax. NF-KB. Apoptosis. Caspace3. Catalase. MDA. Histopathology.

\section{INTRODUCTION}

Accumulation of injurious molecular damages through life leads to a fundamental unavoidable physiological phenomenon that is known as "aging" (Harman, 2001; Harman, 2006). Aging is often accompanied by the atrophy of the skeletal muscle which is a major contributor to muscle weakness (Thompson, 2007). Skeletal muscles play an essential role in locomotion and metabolism as it represents $40 \%$ of total body mass. Through life, it gradually lost fatfree mass, size, and function and as a result causes what is called sarcopenia in aging (Rosenberg, Sarcopenia, 1997). Sarcopenia considers a major health problem

*Correspondence: Abeer A. Alm-Eldeen. Zoology Department. Faculty of Science. Tanta University, Tanta, Egypt. Phone: +201224442938. Email: abeer.eldeen@science.tanta.edu.eg.Email: abeer75875@hotmail.com among aged people. It is accompanied by serious health consequences in terms of disability, weakness, and morbidity (Tsekoura et al., 2017). Beaudart et al. (2014) reported that sarcopenia is also accompanied by some health problems such as poor physical performance, depression, physical disability, hospitalization and functional decline. Finally, it leads to poor quality of life and sometimes to the mortality.

Apoptosis assumes a critical role in the aging process (Higami, Shimokawa, 2000). The rate of the apoptosis is gradually elevated in aged skeletal muscles (Muradian, Schachtschabel, 2001). Apoptosis expands in these cells or organs as a protective mechanism of the organism against aggregation and spread of the defective cells (Salmon, Richardson, Pérez, 2010). The apoptotic changes appeared in aging were due to the continuous exposure to the oxidative stress and free radicals accumulation through the lifespan. Usually, reactive oxygen species 
(ROS) can attack any biochemical component of the cell such as vital proteins, lipids and DNA and consequently promoting and developing the aging process. Oxidative stress results from the decrease in the antioxidant capacity or the increase in ROS production. Catalase (CAT) enzyme activity is known as "endogenous antioxidant" and the first-line defense mechanism against free radical damage. Malondialdehyde activity (MDA) level considers a lipid peroxidation marker that is resulted in cell injury. Thus, it is necessary to exist balancedequilibrium among oxidants and antioxidants defense through lifespan and as early as possible to avoid aging harms (Cutteridhe, 1993; El Barky et al., 2016; AlmEldeen, Donia, Alzahaby, 2018).

In aging, several genes promote apoptosis were down-regulated such as p53 and Bcl-2 genes and caspase family genes including Casp3, Casp8, and Casp9 while, the expression of pro-apoptotic genes such as Bax was upregulated (Alt et al., 2012). (Helenius et al., 2001) tested some aged tissues and recorded an increase in the activity of DNA binding of the nuclear factor-kappa $\mathrm{B}(\mathrm{NF}-\kappa \mathrm{B})$ that resulted from the increase in the components of the nuclear levels of p52 and p65 of NF-кB complex in aged tissues. Cohen (1997) reported that activation of caspase- 3 causes DNA cleavage and fragmentation and consequently cell death. Caspases are a family of proteases that have the main role in the process of the apoptosis. Caspases 8, 9 and 12 stimulate the caspases 3, 6 and 7 to initiate cell disassembly (Fuentes-Prior, Salvesen, 2004).

Quercetin, 3, 3, 4', 5, 7-pentahydroxy flavones, consider polyphenolic compound that is detected exclusively in plants and has the ability to provoke several biological and pharmacological actions. It has the ability also to scavenge the ROS (Patra, Rautray, Swarup, 2011). This is because of its high content of the phenolic hydroxyl groups (Tokyol et al., 2006). It is established that quercetin could control and limit liver fibrosis, hepatotoxicity and cholesterol diminishing factor and several diseases (Khamis et al., 2017). Recently, endothelial apoptotic cells caused by the oxidants can be prevented by quercetin (Renugadevi, Prabu, 2010). However, it is not clear yet if it can be used as a modulator, via increasing the antioxidant defense, against the apoptotic changes that are occurred in the gastrocnemius muscle with age due to the continuous exposure to the oxidative stress. Therefore, the present study was designed to clarify the possible protective role of quercetin against age-induced changes in the transcript level of some apoptosis-related genes in rat's skeletal muscles. Moreover, the examination of the histopathological features of the skeletal muscles was performed too.

\section{MATERIAL AND METHODS}

\section{Animals}

Fifty-six male albino rats of 1, 5, 10 and 15 months old were used in the present study. The rats were housed in plastic cages and maintained under standard conditions of temperature, humidity, and $12 \mathrm{~h}$ light/dark cycle and were provided with a pellet concentrated diet containing all the necessary nutritive elements. Rats were acclimatized for two weeks. The procedures of the experiment were done based on the blinded issue and adhered to the guidelines of the ethical committee of Tanta University, Tanta, Egypt.

\section{Study groups and subgroups}

Fifty-six rats of different ages were used in the present study. The rats were divided into four groups in which each included 14 rats that had 1, 5, 10 and 15 -months-old weighing $28.37 \pm 2.52 \mathrm{~g}, 156.42 \pm 5.56$ $\mathrm{g}, 211.45 \pm 12.14 \mathrm{~g}$ and $336.11 \mathrm{~g} \pm 29.39 \mathrm{~g}$, respectively. Each group at a certain age was then subdivided equally into 2 subgroups; control and quercetin subgroups (7 rats each). Control subgroups include rats which were injected intraperitoneally (i.p.) with a vehicle of dimethyl sulfoxide (DMSO): saline by 1:100. Quercetin subgroups include rats that were injected i.p. with 200 $\mathrm{mg}$ quercetin/kg body weight. The vehicle and quercetin were injected three times/week for 2 weeks (Firdous et al., 2014). Quercetin was purchased from Sigma-Aldrich (St. Louis Mo., U.S.A) and DMSO was purchased from (Fisher scientific UK).

\section{Sampling}

After two weeks, all rats were sacrificed and gastrocnemius muscles were carefully collected under strict hygienic conditions. Samples from four rats at each subgroup were quickly dipping in liquid nitrogen before storing at $-80{ }^{\circ} \mathrm{C}$ to be used for RNA extraction and biochemical analyses. The other samples at each subgroup were fixed in 10\% neutral buffered formalin for histopathological and immunohistochemical examinations. 


\section{Biochemical assays}

Catalase (CAT) enzyme activity was measured according to the method described by (Aebi, 1984). Three reading were taken and the data were expressed as $\mathrm{U} / \mathrm{g}$ protein. Malondialdehyde activity (MDA) level was measured according to the method described by (Ohkawa, Ohishi, Yagi, 1979). Three reading were taken and the results were expressed as $\mathrm{nmol} / \mathrm{g}$ tissue.

\section{RNA isolation and RT-PCR}

Total RNA was extracted from $100 \mathrm{mg}$ of gastrocnemius muscles from 3 different samples using total RNA Purification Kit following the manufacturer protocol (Thermo Scientific, Fermentas, \#K0731) then cDNA was synthesized using Revert Aid H Minus Reverse Transcriptase which is a genetically modified M-MuLV RT (Schmittgen et al., 2000). The isolated cDNA was amplified using 2X Maxima SYBR Green/ ROX qPCR Master Mix following the manufacturer protocol (Thermo Scientific, USA, \# K0221) and gene-specific primers (Table I). Initial activation was performed at $95{ }^{\circ} \mathrm{C}$ for $10 \mathrm{~min}$, followed by 40 cycles of denaturation at $95{ }^{\circ} \mathrm{C}$ for $15 \mathrm{sec}$, annealing at $60{ }^{\circ} \mathrm{C}$ for $30 \mathrm{sec}$ then extension at $72{ }^{\circ} \mathrm{C}$ for $30 \mathrm{sec}$. Data were analyzed using the $2^{-\Delta \Delta \mathrm{Ct}}$ method. The housekeeping gene $(\beta$-actin) was used to calculate the relative gene expression or fold change in the target gene.

TABLE I - Forward and reverse primer sequences for the candidate genes

\begin{tabular}{|c|c|c|}
\hline Gene & $\begin{array}{c}\text { Forward primer } \\
(/ 5---/ 3)\end{array}$ & $\begin{array}{l}\text { Reverse primer } \\
\quad(/ 5---/ 3)\end{array}$ \\
\hline$N F-\kappa B$ & CCTAGCTTTCTCTGAACTGCAAA & GGGTCAGAGGCCAATAGAGA \\
\hline $\operatorname{Bax}$ & ACACCTGAGCTGACCTTG & AGCCCATGATGGTTCTGATC \\
\hline Bcl2 & ATCGCTCTGTGGATGACTGAGTAC & AGAGACAGCCAGGAGAAATCAAAC \\
\hline$\beta$-actin & AAGTCССТСАСССТСССАAAAG & AAGCAATGCTGTCACCTTCCC \\
\hline
\end{tabular}

\section{Histopathological and Immunohistochemical examination}

Gastrocnemius muscle tissues were fixed in a $10 \%$ neutral-buffered formalin solution for at least 24 hours and then embedded in paraffin. Section of $5 \mu \mathrm{m}$ thick was cut, deparaffinized and hydrated. Some sections were stained with hematoxylin and eosin (Bancroft, Cook, Turner, 1994). Other sections were immunohistochemically stained with anti-Caspase-3 using standard streptavidin-biotin-peroxidase complex (ABC) method modified by (Abou-Zaid et al., 2010).
Briefly, sections were dewaxed, hydrated and rinsed in phosphate buffer saline (PBS) twice for 2 minutes each. To block nonspecific background staining due to endogenous peroxidase, slides were incubated in an aqueous solution of $0.3 \%$ hydrogen peroxide for 10 minutes, washed 2 times in PBS buffer. Then, sections were incubated with rabbit anti-CASPASE-3 primary antibody (1:100) (ThermoScientific, Cat no. PA5-16335) overnight at $4{ }^{\circ} \mathrm{C}$ then washed 4 times in PBS. Sections were then incubated with biotinylated rabbit antipolyvalent as a secondary for 2 hours at room temperature then washed 4 times in PBS. The sections were then 
incubated with $\mathrm{ABC}$ (Avidin, Biotin Complex) for 10 minutes at room temperature, rinsed 4 times in PBS. To visualize the reaction, the slides were incubated with 3,3'-Diaminobenzidine (DAB) for 10 minutes at dark then rinsed in PBS three times for 2 minutes each. Slides were counterstained with Mayers hematoxylin, rinsed in running tap water for 10 minutes, dehydrated, cleared and mounted. The positively stained area is brown in color. The sections were photographed then 20 random fields from each group using the objective lens X40 were analyzed for positive caspase- 3 expression. The pixels areas occupied by positive staining in each field in relation to the area of the total pixel in each field were calculated using Adobe Photoshop software (Erekat, Al-Khatib, Al-Jarrah, 2014). Finally, the average area of the pixel occupied by caspase 3 positive staining in relation to the area of the total pixel was calculated for each group.

\section{Statistical analysis}

Statistical analysis of data was carried out using two-way analysis of variance (ANOVA) using GraphPad software followed by Duncan test. Results were expressed as a mean \pm standard error (mean $\pm \mathrm{SE}$ ). $\mathrm{P}$ values less than 0.05 were considered significant. All statistical analyses were performed using SPSS statistical version 16 software package (SPSS ${ }^{\circledR}$ Inc., USA) and Minitab version 12.21).

\section{RESULTS}

\section{Effect of quercetin on CAT and MDA levels}

The data showed a significant reduction $(\mathrm{p} \leq 0.05)$ in the CAT activity of the gastrocnemius muscles in the control subgroups including rats that had 10 and 15 months old compared with the control subgroup including rats that have 1 month old, respectively. Interestingly, quercetin treatment significantly $(\mathrm{p} \leq 0.05)$ increased the CAT activity at the $10^{\text {th }}$ and $15^{\text {th }}$ months and as a result, no significance difference $(p \geq 0.05)$ was noticed in the CAT activity at the $10^{\text {th }}$ and $15^{\text {th }}$ month of age (Figure 1A).

The data revealed that MDA contents in the gastrocnemius muscles of the control subgroups which were injected with a vehicle only were significantly high $(\mathrm{p} \leq 0.05)$ in the rats that had 5,10 and 15 months old compared with the rats that had one month old, respectively. Interestingly, after quercetin administration, no significance difference $(\mathrm{p} \geq 0.05)$ was noticed in the MDA contents neither between the rats that had 1, 5, 10 and 15 months old and were given quercetin nor between them and the rats that had one month old and were given a vehicle only (Figure 1B). 

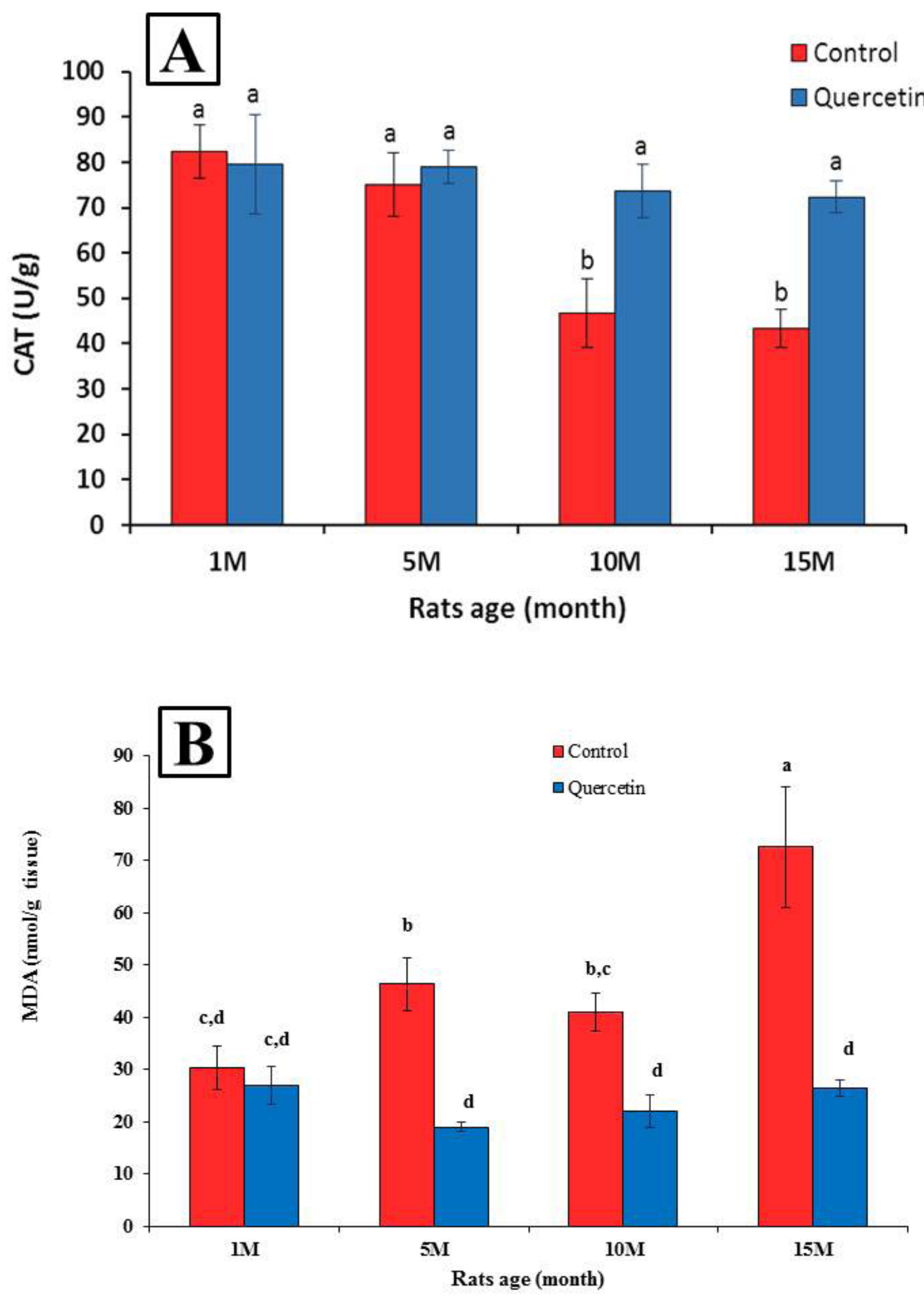

FIGURE 1 - Effect of quercetin on the activity of both CAT and MDA enzymes in the rats that had 1, 5,10 and 15 month old (1 M, $5 \mathrm{M}, 10 \mathrm{M}$ and $15 \mathrm{M}$ ), respectively. Control and quercetin: Rats that were taken a vehicle and quercetin, respectively Data are means \pm SE with $n=3$, Different letters indicate significant differences among the columns $(p \leq 0.05)$. 


\section{Effect of quercetin on the relative expression of $\mathrm{BCl} 2$, Bax, and NF-kB genes}

The data showed a significant $(\mathrm{P} \leq 0.05)$ downregulation in the expression level of $\mathrm{Bcl} 2$ gene in the gastrocnemius muscles with the increase of age in the rats that were given a vehicle only especially at 10 and 15 months old with $0.21 \pm 0.02$ and $0.06 \pm 0.01$ fold change when compared with the rats that had one month old, respectively. After quercetin administration, a significant $(\mathrm{P} \leq 0.05)$ up-regulation in the expression level of the Bcl2 gene was observed in the rats that had $1,5,10$ and 15 months old with $3.41 \pm 0.2,2.60 \pm 0.14$, $1.91 \pm 0.1$ and $1.37 \pm 0.08$ fold change when compared with the rats at the same age that revived a vehicle only, respectively (Figure 2A).

With regard to the expression level of the Bax gene, there is a significant $(\mathrm{P} \leq 0.05)$ up-regulation of its expression level in the gastrocnemius muscles of the rats that had 5, 10 and 15 months old and received a vehicle only, with $1.57 \pm 0.10,1,89 \pm 0.12$ and $2.60 \pm 0.11$ fold change, when compared with the rats that had one month old and received a vehicle only, respectively. After quercetin administration, the data revealed a significant $(\mathrm{P} \leq 0.05)$ down-regulation in the expression level of the Bax gene in the gastrocnemius muscles of the rats that had 1, 5, 10 and 15 months old, with $0.06 \pm 0.01,0.08$ $\pm 0.01,0.15 \pm 0.02$ and $0.65 \pm 0.03$ fold change, when compared with the rats at the same age that revived a vehicle only, respectively (Figure 2B).

The data also showed a significant $(\mathrm{P} \leq 0.05)$ upregulation in the expression level of NF- $\mathrm{KB}$ gene in the gastrocnemius muscles in the rats that had 5, 10, 15 month old that received a vehicle only, with $2 \pm 0.11,3.27$ \pm 0.13 and $4.79 \pm 0.23$ fold change, when compared with rats that had one month old and received a vehicle only, respectively. After quercetin administration, the results revealed a significant $(\mathrm{P} \leq 0.05)$ down - regulation in the expression level of NF- $\kappa \mathrm{B}$ gene in the gastrocnemius muscles of the rats that had 1, 5, 10 and 15 months old, with $0.31 \pm 0.01,0.50 \pm 0.01,0.71 \pm 0.06$ and $0.88 \pm$ 0.05 fold change, when compared with the rats at the same age that received a vehicle only, respectively. Interestingly, the expression level of NF- $\kappa \mathrm{B}$ gene in the gastrocnemius muscles showed a non-significant $(\mathrm{P} \geq$ $0.05)$ change between the rats that had 15 months old and received quercetin and the control rats that had of 1 month old and received a vehicle only. Furthermore, a non-significant change $(P \geq 0.05)$ was noticed in the expression level of this gene in the gastrocnemius muscles of the rats that had 5,10 and 15 months old after quercetin administration (Figure 2C). 

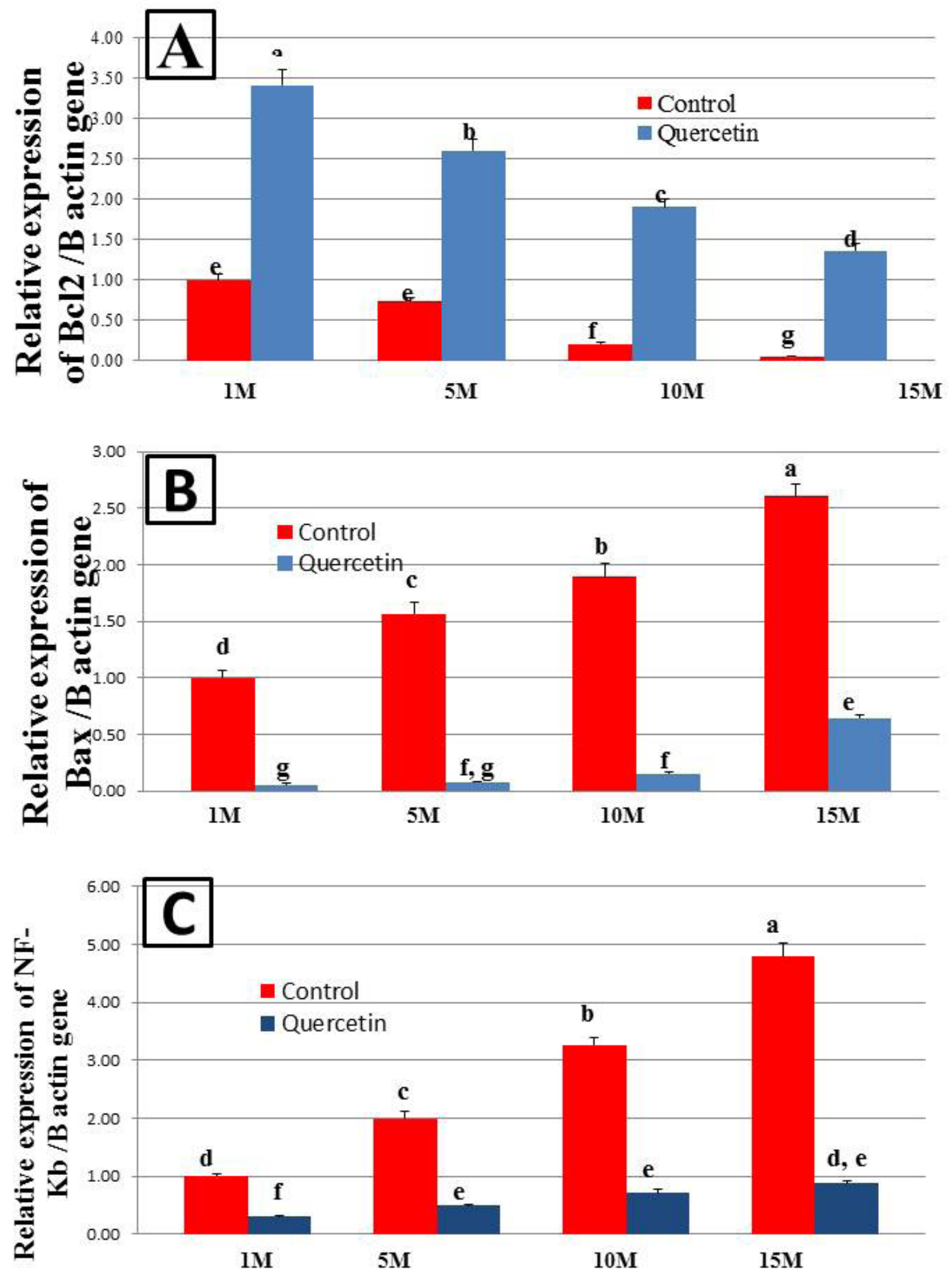

FIGURE 2 - Graphical presentation of a real-time quantitative PCR analysis of Bcl2, Bax and NF- $\kappa \mathrm{B}$ genes in the gastrocnemius muscles of the rats that had 1, 5, 10 and 15 month old (1 M, $5 \mathrm{M}, 10 \mathrm{M}$ and $15 \mathrm{M})$, respectively. Control and quercetin: Rats that were taken a vehicle and quercetin, respectively Data are means $\pm S E$ with $n=3$, Different letters indicate significant differences among the columns $(\mathrm{p} \leq 0.05)$. 


\section{Effect of quercetin on the histopathological picture}

Observation of the rat's gastrocnemius muscles in the control subgroups, including rats that were received a vehicle only, revealed the normal architecture of the muscle fibers in the rats that had one month old. Focal myolysis of the muscle fibers was rarely observed (Figure 3A).

Rats that had 5 months old revealed that some muscle had cellular infiltration, fragmentation or marked disruption. Moreover, areas of sarcoplasm hyalinization were sometimes noticed in some fibers (Figure 3B). Rats that had 10 months old showed marked hyalinization of the muscle fibers. Furthermore, fragmentation and disruption of some muscle fibers were also noticed (Figure 3C). Rats that had 15 months old showed severe hyalinization of the muscle fibers associated with hyperplasia of adipocytes (Figure 3D). After quercetin administration, gastrocnemius fibers of the rats that had one and 5 months old appeared with normal architecture and muscles' myolysis, infiltration and fragmentation were rarely observed (Figure 3E, F). Interestingly, rats had 10 and 15 months old showed just focal hyalinization of the muscle fibers while most gastrocnemius fibers appeared with normal appearance (Figure 3G, H).

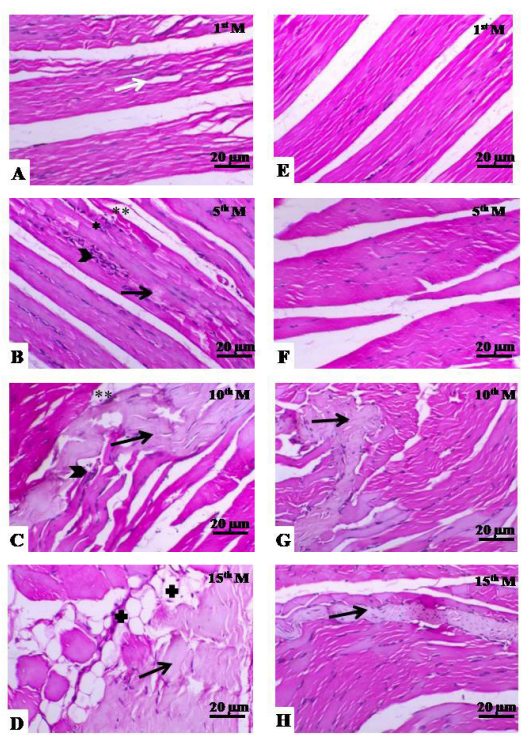

FIGURE 3 - Light photomicrographs of the rats gastrocnemius muscles stained with hematoxylin and eosin. (A- D) and (E$\mathrm{H})$ : Rats that were taken a vehicle and quercetin, respectively. 1stM, 5thM, 10thM and 15thM include rats that had 1, 5, 10 and 15 month old, respectively. Note Focal myolysis (white arrow), cellular infiltration (arrowhead), Fragmentation (*), disruption (**), hyalinization (black arrow) of the muscle fibers and hyperplasia of adipocytes $(+)$.

\section{Effect of quercetin on the CASPASE-3 immunostaining}

Examination of the rats gastrocnemius muscle sections that received a vehicle only revealed a significant increase $(\mathrm{p} \leq 0.05)$ in the positive immunohistochemical expression of CASPASE-3 in the rats that had 5, 10 and 15 month old when compared with the rats that had one month old and when compared with each other respectively (Figure 4). The mean pixels area $/ \mathrm{mm}^{2}$ of positive CASPASE-3 staining were $0.27 \pm 0.08,0.53$ $\pm 0.21,0.63 \pm 0.19$ and $0.81 \pm 0.29$ in the rats that had 1, 5, 10 and 15 month old, respectively. Examination of the rat's gastrocnemius muscle sections that had $1,5,10$ and 15-months-old and received quercetin showed a significant $(\mathrm{p} \leq 0.05)$ decrease in the immunohistochemical expression of caspase 3 when compared with the rats at the same age that received a vehicle only, respectively (Figure 4).The mean pixels area $/ \mathrm{mm}^{2}$ of positive caspase 3 staining were $0.04 \pm$ $0.02,0.09 \pm 0.04,0.11 \pm 0.03$ and $0.42 \pm 0.19$ in the rats that had 1, 5, 10 and 15 month old, respectively.

This study was designed to clarify the possible protective role of quercetin against gastrocnemius muscle changes accompanied by age in male rats. The rats that received a vehicle only showed a reduction in the gastrocnemius CAT activity at the $10^{\text {th }}$ and $15^{\text {th }}$ month of age while showed a significant increase in its MDA level at the $5^{\text {th }}, 10^{\text {th }}$ and $15^{\text {th }}$ month of age when compared with the rats that have one month old, respectively. They showed also significant down -regulation of $\mathrm{Bcl} 2$ gene and significant up-regulation of Bax and NF- $\kappa \mathrm{B}$ genes and caspase 3 protein with the increase of age. At the $10^{\text {th }}$ and $15^{\text {th }}$ month of age, severe hyalinization of the muscle fibers associated with hyperplasia of adipocytes was often determined. These results were consistent with (Vaux, Korsmeyer, 1999) who reported that characteristic changes in the phenotype occur in all individuals with age over time. Aging is frequently depicted as a process of a progressive decrease in the organs/organism capacity due to the accumulation of harmed cells (Shalini et al., 2015). With age, ROS are generating and as a result, several cumulative injuries exist. By adding single electrons, some oxygen is reduced and converted into ROS which consequently can cause extensively molecular injuries to the nucleic acids, proteins, and lipids (Harman, 2006). This explains the molecular injuries that we observed in the gastrocnemius muscles in the present study with age. 

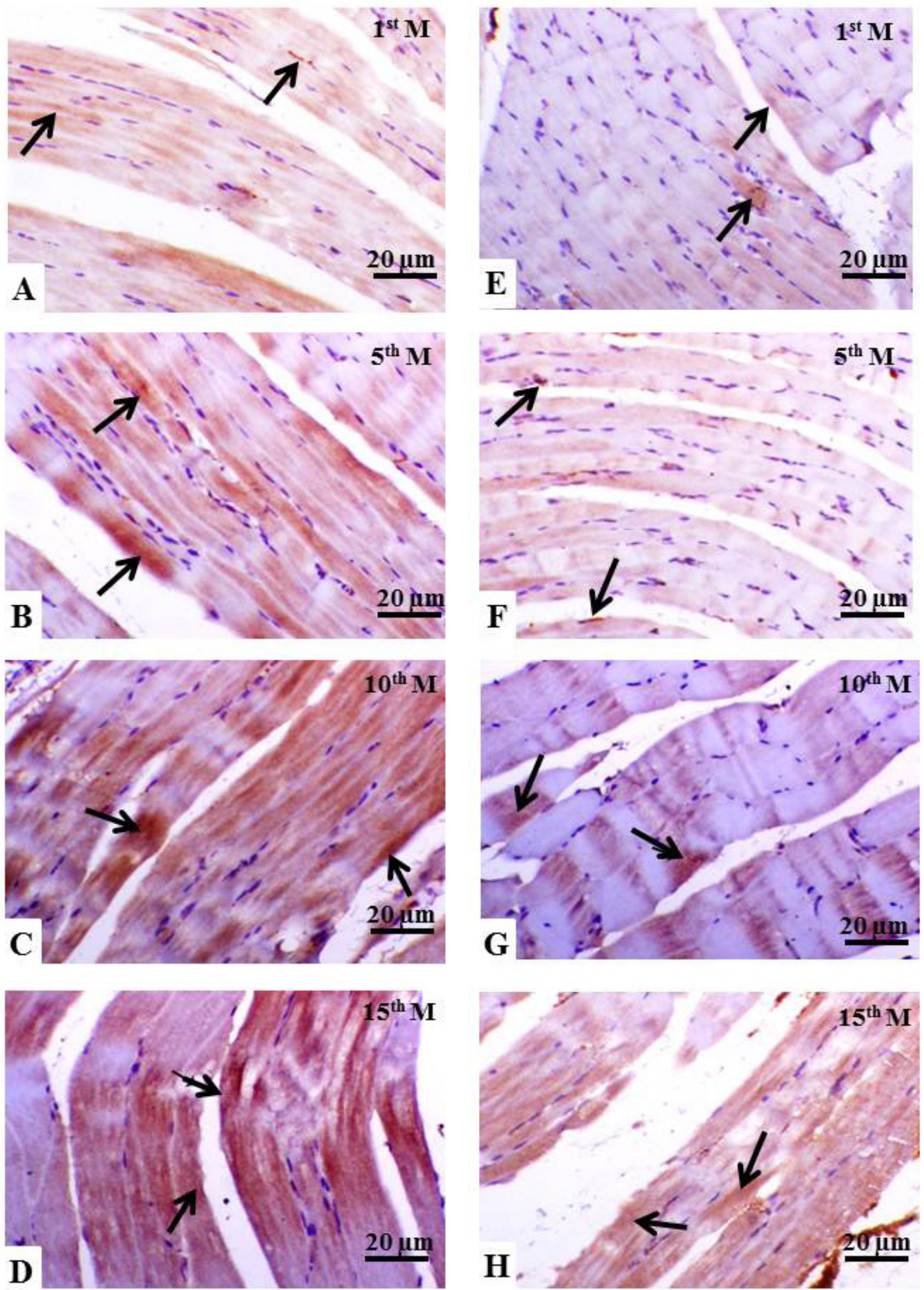

FIGURE 4: Light photomicrographs of the rats gastrocnemius muscles immunostained with caspase 3 antibodies. (A- D) and (E$\mathrm{H})$ : Rats that were taken a vehicle and quercetin, respectively. 1stM, 5thM, 10thM and 15thM include rats that had 1, 5, 10 and 15 month old, respectively. Note the increase of caspase 3 expressions (arrows) from A to D then the decrease of its expression (arrows) from $\mathrm{E}$ to $\mathrm{H}$. Note also the difference in the caspase 3 expression, at the same age, after quercetin adminsitration. 


\section{DISCUSSION}

Generally, CAT is a primary enzymatic defense against $\mathrm{H}_{2} \mathrm{O}_{2}$ generation and MDA level considers a marker for lipid peroxidation and could reflect oxygen radical production (Gülçin et al., 2009). This may explain why the deteriorated changes started at the $5^{\text {th }}$ month with the increase of the MDA activity followed by the decrease of the CAT activity at the $10^{\text {th }}$ month. CAT is known as "endogenous antioxidant" and the firstline defense mechanism against free radical damage (El Barky et al., 2016: Birdane et al., 2007). In addition, lipid peroxidation resulted in cellular injury causes structural and functional alterations in the cells (Henderson et al., 2010; Tousson, Alm-Eldeen, El-Moghazy, 2011; AlmEldeen et al., 2017). However, more data are needed to be collected monthly to determine precisely when CAT starts to be decreased.

The present down-regulation of $\mathrm{Bcl} 2$ and upregulation of Bax genes and caspase- 3 protein in the aged gastrocnemius that received a vehicle only are in agreement with (Alway et al. 2002) who recorded an elevation of Bax and caspase-3 protein expression and $\mathrm{Bax} / \mathrm{Bcl}-2$ ratio in aged skeletal muscle due to the oxidative stress exposure. They showed that the deregulation of $\mathrm{Bcl}-2$ pathway signaling leads to CASPASE-3 activation and intrinsic apoptotic pathways in aged skeletal muscle. Furthermore, (Song et al., 2012) found that the mitochondrial $\mathrm{Bcl}-2$ protein levels were reduced by $20 \%$ in aged rats compared to young rats, although the mitochondrial Bax protein level was $11 \%$ higher in aged rats compared to young rats. Moreover, the ratio of $\mathrm{Bcl} 2 / \mathrm{Bax}$ in the gastrocnemius was increased by $98 \%$ in aging. They added that caspase- 3 mRNA content was $72 \%$ higher in rats with 22 months old than the rats with 4 months old. Apoptosis can be regulated essentially by the mitochondria via $\mathrm{p} 53$ and $\mathrm{Bcl} 2$ proteins that including $\mathrm{Bax}$ and $\mathrm{Bcl} 2$ (Siu, Alway, 2005). Several deteriorated changes appeared as a result of the activity of caspases (Zhang, Zhang, Herman, 2003). In addition, proteolytic cleavage of many of the cellular proteins is caused by caspase 3. (Fischer et al., 2003) reported that cells' death is caused by the apoptotic changes resulted from proteolysis. The upregulation of NF- $\mathrm{KB}$ in the gastrocnemius muscles with age in the present study is consistent with (Zhang et al., 2004) who reported that NF- $\kappa B$ activation seems to be a generalized phenomenon in aging as it was observed in the skeletal muscle, liver, brain, and cardiac muscle of aged rats. (Csiszar et al., 2008) stated that NF-кB is a redox-sensitive transcription factor that plays an important role in the inflammatory phenotypic change in endothelial and smooth muscle cells in various pathophysiological conditions.

The current improvement in both biochemical (increased the CAT and decreased the MDA activities), molecular (increased the expression of $\mathrm{Bcl} 2$ and decreased the expression of both Bax and NF- $\kappa \mathrm{B}$ genes and caspase 3 protein) and histological pictures of aged gastrocnemius muscles after quercetin treatment agreed with (Ekinci Akdemir et al. 2016) who found that tissue MDA levels were increased in the rat's muscle tissue in ischemia-reperfusion (IR) injury group compared with the sham group and quercetin could be able to decrease it. They added that quercetin treatment significantly attenuated the amount of lipid peroxidation by increasing the levels of antioxidant enzyme and reducing the formation of free radical or sweeping of free radical. In the same line, quercetin has been showed to have a protective effect against oxidative stress in the hepatic tissues by increasing the ratio of GSH/GSSG (Molina et al., 2003). Dietary quercetin could up-regulated GSH/GSSG ratio in the liver (Meyers, Rudolf, Mitchell, 2008). quercetin has been recorded to obviously, induce the expression of CAT gene as well as enhanced its enzyme activities while reduced the increased MDA level (Almaghrabi, 2015). This is because of its ability to scavenge the ROS (Patra, Rautray, Swarup, 2011) via its high content of the phenolic hydroxyl groups (Tokyol et al., 2006).

The present up-regulation of $\mathrm{Bcl} 2$ and the down - regulation of Bax in the rat's gastrocnemius muscles following quercetin administration confirmed the potential antioxidant effect of quercetin against ageinduced changes by stimulating the expression of the anti-apoptotic $\mathrm{Bcl} 2$ gene and suppressing the expression of the pro-apoptotic Bax gene. This improvement may explain the ability of quercetin, a member of the flavonoids family that has been shown to possess antioxidant activities by attributing to the quenching of free radicals, lipid peroxides and interact with membrane lipid components, with a resultant protection of the membranes against oxidative damage (Zhang et al., 2015), thereby preserving the normal cell functions and face the molecular changes produced with aging (Atalık et al., 2010). With regard to the mechanism by which quercetin modulated NF- $\kappa \mathrm{B}$ activity, (Ying et al., 2009) found that NF- $\mathrm{BB}$ is inactive in the cytoplasm 


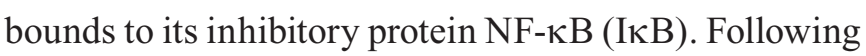
a stimulus, a signaling cascade is triggered resulting in

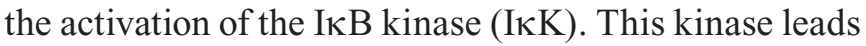
to phosphorylation and degradation of $\mathrm{I} \kappa \mathrm{B}$, releasing $\mathrm{NF}-\kappa \mathrm{B}$ to the nucleus.

In conclusion, age-related muscle changes is a very complex process includes histological, biochemical and molecular changes. This is due to continuous exposure to oxidative stress. quercetin is a potent antioxidant possesses the capacity to protect against age-induced changes by increasing the CAT level and the expression of $\mathrm{Bcl} 2$ gene which acts as an anti-apoptotic factor and decreasing the MDA level and down-regulate the expression of both NF- $\kappa \mathrm{B}$ and $\mathrm{Bax}$ genes as pro-apoptotic factors and caspase- 3 protein which is executioner effector. Finally, quercetin, as a potent antioxidant agent, could be used as anti-aging modulator against age-induced deteriorated changes in the gastrocnemius muscles that resulted from the continuous exposure to the oxidative stress via managing changes in the transcript level of some apoptosis-related genes.

\section{CONFLICTS OF INTEREST}

The authors declare that there is no conflict of interest.

\section{REFERENCES}

Abou-zaid FA, Salem SB, Madkour GA, Alm-Eldeen AA. Histological and immunohistochemical studies on the pigeon endocrine pancreas at different ages. Egypt J Exp Biol. 2010;6(1):385-94.

Aebi H. Catalase in vitro. In: Methods enzymol. 1984;105:121126. Academic Press.

Alm-eldeen AA, Basyony MA, Elfiky NK, Andghalwash MM. Effect of the Egyptian propolis on the hepatic antioxidant defense and pro-apoptotic p53 and anti-apoptotic bcl2 expressions in aflatoxin B1 treated male mice. Biomed Pharmacother. 2017;v(1):247-55.

Alm-Eldeen AA, Donia T, Alzahaby, S. Comparative study on the toxic effects of some heavy metals on the Nile Tilapia, Oreochromis niloticus, in the Middle Delta, Egypt. Environ Sci Pollut Res Int. 2018;25(15): 14636-46.

Almaghrabi OA. Molecular and biochemical investigations on the effect of quercetin on oxidative stress induced by cisplatin in rat kidney. Saudi J Biol Sci. 2015;22(2):227-31.
Alt EU, Senst C, Murthy SN, Slakey DP, Dupin CL, Chaffin AE, et al. Aging alters tissue resident mesenchymal stem cell properties. Stem Cell Res. 2012; 8(2):215-2.

Alway SE, Degens H, Krishnamurthy G, Andsmith CA. Potential role for Id myogenic repressors in apoptosis and attenuation of hypertrophy in muscles of aged rats. Am J Physiol Cell Physiol. 2002;283(1):C66-76.

Atalik K, Keleş B, UYAR Y, DÜNDAR M, ÖZ M, ANDESEN $\mathrm{H}$. Vasoprotection by melatonin and quercetin in rats treated with cisplatin. Indian J Exp Biol. 2010;48(12):1188-93.

Bancroft JD, Cook H, Andturner D. (1994). Manual of Histological Techniques and Their Diagnostic Application, 2e. Churchill Livingstone; 1994.

Beaudart C, Reginster JY, Slomian J, Buckinx F, Locquet M, Bruyère $\mathrm{O}$. Prevalence of sarcopenia: the impact of different diagnostic cut-off limits. J Musculoskelet Neuronal Interact. 2014;14(4):425-31.

Birdane FM, Cemek M, Birdane YO, Gülçin İ, Andbüyükokuro lu, ME. Beneficial effects of Foeniculum vulgare on ethanol-induced acute gastric mucosal injury in rats. World j Gastroenterol. 2007;13(4):607-11.

Cohen GM. Caspases: the executioners of apoptosis. Biochem J. 1997; 326(1):1-16.

Csiszar A, Wang M, Lakatta EG, Andungvari Z. Inflammation and endothelial dysfunction during aging: role of NF-кB. J Appl Physiol. 2008;105(4):1333-41.

Cutteridhe J. Free radicals in disease processes: a compilation of causes and consequences. Free Rad Res Commun. 1993;19(3):141-50.

Ekinci Akdemir FN, Gülçin İ, Karagöz B, Andsoslu R. Quercetin protects rat skeletal muscle from ischemia reperfusion injury. J Enzyme Inhib Med Chem. 2016;31(2) $162-66$.

El Barky AR, Hussein SA, Alm-Eldeen AA, Hafez YA, Mohamed, TM. Anti-diabetic activity of Holothuria thomasi saponin. Biomedicine Pharmacother. 2016;84(1):1472-87.

Erekat N, Al-KhatibA, Andal-Jarrah M. Heat shock protein 90 is a potential therapeutic target for ameliorating skeletal muscle abnormalities in Parkinson's disease. Neural Regen Res. 2014;9(6):616-21.

Firdous A, Sharmila G, Balakrishnan S, Rajasingh P, Suganya $\mathrm{S}$, Srinivasan N, et al. Quercetin, a natural dietary flavonoid, acts as a chemopreventive agent against prostate cancer in 
an in vivo model by inhibiting the EGFR signaling pathway. Food Funct. 2014;5(10):2632-45.

Fischer U, Jänicke R, Andschulze-Osthoff K. Many cuts to ruin: a comprehensive update of caspase substrates. Cell Death Differ. 2003;5(10):76-100.

Fuentes-Prior P, Salvesen GS. The protein structures that shape caspase activity, specificity, activation and inhibition. Biochem J. 2004;384(2):201-32.

Gülçin İ, Beydemir Ş, Hisar O, Köksal E, Andreiter RJ. Melatonin administration increases antioxidant enzymes activities and reduces lipid peroxidation in the rainbow trout (Oncorhynchus mykiss, Walbaum) erythrocytes. Tur J Vet Anim Sci. 2009;33(1):241-45.

Harman D. Aging: overview. Ann N Y Acad Sci. 2001;928(1):1-21.

Harman D. Free radical theory of aging: an update. Ann N Y Acad Sci. 2006;1067(1): 10-21.

Helenius M, Kyrylenko S, Vehviläinen P, Salminen A. Characterization of aging-associated up-regulationof constitutive nuclear factor-kappa b binding activity. Antioxid redox signal. 2001;3(1):147-56.

Henderson PW, Singh SP, Weinstein AL, Nagineni V, Rafii DC, Kadouch D, et al. Therapeutic metabolic inhibition: hydrogen sulfide significantly mitigates skeletal muscle ischemia reperfusion injury in vitro and in vivo, Plast Reconstr Surg. 2010;126(6):1890-98.

Higami Y, Shimokawa I. Apoptosis in the aging process. Cell Tissue Res. 2000;301(1):125-32.

Khamis AA, Salama AF, Kenawy ME, Mohamed TM. Regulation of hepatic hydroxy methyl glutarate-CoA reductase for controlling hypercholesterolemia in rats. Biom Pharmacother. 2017;95(1):1242-50.

Meyers KJ, Rudolf JL, Mitchell AE. Influence of dietary quercetin on glutathione redox status in mice. J Agric Food Chem. 2008;56(3):830-36.

Molina MF, Sanchez-Reus I, Iglesias I, Benedi J. Quercetin, a flavonoid antioxidant, prevents and protects against ethanolinduced oxidative stress in mouse liver. Bio Pharm Bull. 2003;26(10):1398-1402.

Muradian K, Schachtschabel D. The role of apoptosis in aging and age-related disease: update. $Z$ für Gerontol Geriatr. 2001;34(6):441-46.
Ohkawa H, Ohishi N, Yagi K. Assay for lipid peroxides in animal tissues by thiobarbituric acid reaction. Anal Biochem.1979;95(2):351-58.

Patra R, Rautray AK, Swarup D. Oxidative stress in lead and cadmium toxicity and its amelioration. Vet Med Int. 2011;2011(1):1-10

Renugadevi J, Prabu SM. Quercetin protects against oxidative stress-related renal dysfunction by cadmium in rats. Exp Toxicol Pathol. 2010;62(5):471-81.

Rosenberg i H. Sarcopenia: origins and clinical relevance. J Nutr. 1997;127(5):990S-991S.

Salmon AB, Richardson A, Pérez VI. Update on the oxidative stress theory of aging: does oxidative stress play a role in aging or healthy aging? Free Radic Biol Med. 2010;48(5):642-55.

Schmittgen TD, Zakrajsek BA, Mills AG, GORN V, SINGER, MJ, ANDREED MW. Quantitative reverse transcription-polymerase chain reaction to study mRNA decay: comparison of endpoint and real-time methods. Anal Biochem. 2000;285(2):194-204.

Shalini S, Dorstyn L, Dawar S, Kumar S. Old, new and emerging functions of caspases. Cell Death Differ. 2015;22(4):526-39.

Siu PM, Alway SE. Mitochondria-associated apoptotic signalling in denervated rat skeletal muscle. J Physiol. 2005;565(1): 309-23.

Song W, Ko KJ, Shin SJ, Ryu DS. Penile abscess secondary to neglected penile fracture after intracavernosal vasoactive drug injection. World J Mens Health. 2012;30(3):189-91.

Thompson D. Aging and sarcopenia. J Musculoskelet Neuronal Interact. 2007;7(4):344-45.

Tsekoura M, Kastrinis A, Katsoulaki M, Billis E, Gliatis J. Sarcopenia and Its Impact on Quality of Life. Adv Exp Med Biol. 2017; 987:213-218.

Tokyol C, Yilmaz S, Kahraman A, Cakar H, Polat C. The effects of desferrioxamine and quercetin on liver injury induced by hepatic ischaemia-reperfusion in rats. Acta Chir Belg. 2006;106(1):68-72.

Tousson E, Alm-Eldeen A, El-Moghazy M. p53 and Bcl2expression in response to boldenone induced liver cells injury. Toxicol Ind Health. 2011;27(8):711-18.

Vaux DL, Korsmeyer SJ. Cell death in development. Cell. 1999;96(2):245-54. 
Quercetin modulates age-induced changes in the transcript levels of some apoptosis related genes in the skeletal muscles of male rats

Ying B, Yang T, Song X, Hu X, Fan H, Lu X, et al. Quercetin inhibits IL-1 beta-induced ICAM-1 expression in pulmonary epithelial cell line A549 through the MAPK pathways. Mol Biol Rep. 2009;36(7):1825-32.

Zhang JH, Zhang Y, Herman B. Caspases, apoptosis and aging. Ageing Res Rev. 2003;2(4):357-66.
Zhang J, Dai J, Lu Y, Yao Z, O’brien CA, Murtha JM, et al. In vivo visualization of aging-associated gene transcription: evidence for free radical theory of aging. Exp Gerontol. 2004;39(2):239-47.

Zhang, Y.; Chen, X.; Yang, L.; Zu, Y.; LU, Q. Effects of rosmarinic acid on liver and kidney antioxidant enzymes, lipid peroxidation and tissue ultrastructure in aging mice. Food Funct. 2015;6(3):927-31.

Received for publication on $30^{\text {th }}$ October 2018 Accepted for publication on $16^{\text {th }}$ May 2019 